\title{
BMJ Open Impact of faecal haemoglobin concentration on colorectal cancer mortality and all-cause death
}

Li-Sheng Chen, ${ }^{1}$ Amy Ming-Fang Yen, ${ }^{1}$ Callum G Fraser, ${ }^{2}$ Sherry Yueh-Hsia Chiu, ${ }^{3}$ Jean Ching-Yuan Fann, ${ }^{4}$ Po-En Wang, ${ }^{5}$ Sheng-Che Lin, ${ }^{6}$ Chao-Sheng Liao, ${ }^{7}$ Yi-Chia Lee, ${ }^{8}$ Han-Mo Chiu, ${ }^{8}$ Hsiu-Hsi Chen ${ }^{9}$

To cite: Chen L-S, Yen AM-F, Fraser CG, et al. Impact of faecal haemoglobin concentration on colorectal cancer mortality and allcause death. BMJ Open 2013;3:e003740

doi:10.1136/bmjopen-2013003740

- Prepublication history for this paper is available online. To view these files please visit the journal online (http://dx.doi.org/10.1136/ bmjopen-2013-003740).

Received 5 August 2013 Revised 2 September 2013 Accepted 24 September 2013

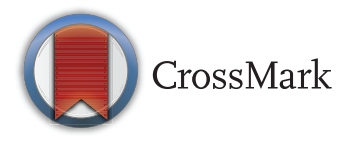

For numbered affiliations see end of article.

Correspondence to Professor Hsiu-Hsi Chen; chenlin@ntu.edu.tw

\section{ABSTRACT}

Objective: To assess the effect of an incremental increase in faecal haemoglobin $(\mathrm{f}-\mathrm{Hb})$ concentration on colorectal cancer (CRC) mortality and all-cause death. Design: We conducted an observational study of cohorts over time based on two population-based CRC screening programmes.

Setting: Two cities of Taiwan.

Participants: 1233 individuals with CRC (217 prevalent cases and 1016 incident cases) and 2640 with colorectal adenoma (1246 prevalent cases and 1394 incident cases) found in the two cohorts of 59767 and 125976 apparently healthy individuals, aged 40 years and above, who had been invited to participate in screening since 2001 and 2003, respectively.

Main outcome measures: Death from CRC and all-cause death ascertained by following up from the entire two cohorts over time until 2009.

Results: The effect of an incremental increase in $\mathrm{f}-\mathrm{Hb}$ on the risk for CRC mortality was noted, increasing from a slightly increased risk for the category of $\mathrm{f}-\mathrm{Hb}$ of $20-49 \mathrm{ng} \mathrm{Hb} / \mathrm{mL}$ (adjusted HR (aHR) $=1.09 ; 95 \% \mathrm{Cl}$ 0.68 to 1.75$)$ to $11.67(95 \% \mathrm{Cl} 7.71$ to 17.66$)$ for the group with $\mathrm{f}-\mathrm{Hb} \geq 450 \mathrm{ng} \mathrm{Hb} / \mathrm{mL}$ as compared with the group considered baseline with $\mathrm{f}-\mathrm{Hb}$ of $1-19 \mathrm{ng} \mathrm{Hb} / \mathrm{mL}$ $(p<0.001)$. A similar but less marked increasing trend was found for all-cause mortality, aHR increasing from $1.15(95 \% \mathrm{Cl} 1.07$ to 1.24$)$ for the group with $\mathrm{f}-\mathrm{Hb}$ of $20-49 \mathrm{ng} \mathrm{Hb} / \mathrm{mL}$ to 1.67 (95\% Cl 1.54 to 2.07 ) for the group with $\mathrm{f}-\mathrm{Hb} \geq 450 \mathrm{ng} \mathrm{Hb} / \mathrm{mL}$.

Conclusions: We substantiated the impacts of an incremental increase in $\mathrm{f}-\mathrm{Hb}$ on the risk for death from CRC and all-cause death, consistently showing a significant gradient relationship. Both discoveries suggest that $\mathrm{f}-\mathrm{Hb}$ may not only make contribution to facilitating individually tailored screening for CRC but also can be used as a significant predictor for life expectancy.

\section{INTRODUCTION}

Use of traditional guaiac faecal occult blood tests (gFOBTs) has been shown to reduce mortality in population-based screening

\section{Strengths and limitations of this study}

- The results were derived from the two large longitudinal cohorts of individuals, making allowance for other possible confounding correlates.

- The effect of an incremental increase in faecal haemoglobin ( $\mathrm{f}-\mathrm{Hb})$ concentration on colorectal cancer mortality and all-cause death were demonstrated in a dose-dependent fashion.

- The gradient relationship between $\mathrm{f}-\mathrm{Hb}$ concentration and death from colorectal cancer can be applied to individually tailored screening for colorectal cancer.

- These findings require longer follow-up time and other longitudinal cohorts to verify.

programmes for colorectal cancer (CRC), ${ }^{1} 2$ this test is now considered obsolete by many. ${ }^{3}$ The newer faecal immunochemical tests (FITs) for haemoglobin ( $\mathrm{Hb}$ ) have many advantages, ${ }^{4}$ are recommended in recent guidelines, ${ }^{5} 6$ and have been introduced in many countries. Moreover, there are plans to begin screening using FIT in other countries, and those that still use gFOBT are planning to evolve their programmes and adopt FIT. Quantitative FIT values, generally using automated immunoturbidimetric analytical systems, have the significant advantage that they allow the end-user to select the faecal haemoglobin ( $\mathrm{f}-\mathrm{Hb})$ to be used as the cut-off for referral for further investigation, usually colonoscopy. Previous study has shown that, as the cut-off concentration is decreased, positivity and sensitivity increase at the expense of specificity and positive predictive value. ${ }^{7}$ Moreover, there is some evidence, from data generated in screening programmes using FIT, that $\mathrm{f}-\mathrm{Hb}$ is directly related to the severity of colorectal disease present in those screened. ${ }^{8-10}$

In nearly all screening programmes, quantitative FIT is used simply as a qualitative investigation to identify participants with 
$\mathrm{f}-\mathrm{Hb}$ above a predetermined cut-off concentration chosen to suit the requirements of the particular programme, such as the colonoscopy resource available. However, a recent study has demonstrated the potential usefulness of using baseline $\mathrm{f}-\mathrm{Hb}$ in predicting the risk of colorectal neoplasia in those who attend screening but who are classified as negative at first screen and are therefore not further investigated at that time. ${ }^{11}$ This observed trend for increasing $\mathrm{f}-\mathrm{Hb}$ to be associated with increasing risk of colorectal neoplasia prompted us to speculate whether the causal effect of $\mathrm{f}-\mathrm{Hb}$ on CRC mortality might also exist. It also would be of interest to elucidate whether a greater risk of $\mathrm{f}-\mathrm{Hb}$ can lead to higher all-cause death. To our knowledge, these have never been investigated to date.

The aim of this study was to assess whether the effect of an incremental increase in $\mathrm{f}-\mathrm{Hb}$ on the risk of death from CRC could be found in a population that has undergone screening using FIT and has been followed up for 3.5 years of median follow-up period. The impact of an incremental increase in $\mathrm{f}-\mathrm{Hb}$ on all-cause death was also explored.

\section{MATERIALS AND METHODS \\ Study cohorts}

The study population comprised two cohorts who had been offered population-based screening for CRC using FIT: the first were residents of Keelung city, which is situated in the North of Taiwan, and the second resided in Tainan county, which is situated in the far South. Both cohorts underwent screening for CRC as part of community-based integrated screening programmes, in which tests for five neoplastic and three non-neoplastic diseases were performed. The details of study design, screening protocol, policy for referrals and diagnostics, surveillance and the evaluation of outcomes have been described in full elsewhere. ${ }^{12}$ Some characteristics of the two cohorts are delineated as follows.

The Keelung cohort included participants in the Keelung community-based integrated screening programme from 1999 until present. The details of the screening protocol for CRC have been presented in previous reports. ${ }^{11} 13{ }^{14}$ In brief, the screening population comprised residents aged 40-79 years who were screened at yearly intervals until 2008, and then biennially. There were 59767 participants and entry since 2001 into the programme was staggered: 30005 (50.2\%) attended two or more screening sessions (subsequent screens) during the 9-year period, which facilitates our analysis over time using repeated measurements of $\mathrm{f}-\mathrm{Hb}$. Note that although the community-based screening programme started from 1999, quantitative f-Hb information could only be made available since 2001. Before 2001, only qualitative results could be obtained. This cohort was followed up from the entry of the study to the end of 2009 and cases of CRC, colorectal adenoma and death ascertained. The primary endpoints included death from CRC (coded as ICD 153 and 154) and allcause death.

The second cohort was from Tainan, Taiwan, and the screening design, protocol, procedures for referral, surveillance and follow-up are very similar to that used in the Keelung programme. ${ }^{12}$ Tainan, located in the South of Taiwan, is an agricultural area and somewhat different from suburban areas in Keelung. The major difference between the cohorts is that the screening rate was higher in Keelung than Tainan. This is because the screening programme in Tainan covered a larger population and started later. The Tainan cohort has been screened on an annual basis since 2003. The cohort included 125976 study participants aged 40 years and above: 35797 (28.4\%) attended two or more screens. The Tainan cohort was followed up from entry to the study until the end of 2009. All participants provided written informed consent.

\section{FIT for $\mathrm{Hb}$}

The FIT was based on the OC Sensor method (Eiken Chemical Company, Tokyo, Japan), a widely used quantitative immunoturbidimetric methodology for measuring $\mathrm{f}-\mathrm{Hb}$. Details of the methodology that we used have been described elsewhere. ${ }^{11}$ In brief, in our community screening programme, a single faecal sample $(c .10 \mathrm{mg}$ taken from a faecal sample using the serrated tip of the probe that is integral to the specimen collection device cap) was collected into $2 \mathrm{~mL}$ preservative buffer in the specimen collection device by trained public health nurses following standard procedures. Once collected, samples were stored at room temperature and returned to community health centres within 3 days, and then refrigerated at $4^{\circ} \mathrm{C}$. All samples were then sent to the central laboratory at ambient temperature within 7 days of screening. The $\mathrm{f}-\mathrm{Hb}$ results were reported as $\mathrm{ng} \mathrm{Hb} / \mathrm{mL}$ ( $5 \mathrm{ng} \mathrm{Hb} / \mathrm{mL}=1 \mu \mathrm{g} \mathrm{Hb} / \mathrm{g}$ faeces) and the results recorded in the central laboratory. When samples were assessed with high $\mathrm{Hb}$ concentrations (>1000 $\mathrm{ng} \mathrm{Hb} / \mathrm{mL}$ ) the analyser flagged out of range results for subsequent automated serial dilution for reanalysis to give quantitative $\mathrm{f}-\mathrm{Hb}$ results ranging from 0 to $250000 \mathrm{ng} \mathrm{Hb} / \mathrm{mL}$. The cut-off used to select individuals for further investigation using colonoscopy was $100 \mathrm{ng} \mathrm{Hb} / \mathrm{mL}$.

\section{Data collection}

Participants with $\mathrm{f}-\mathrm{Hb} \geq 100 \mathrm{ng} \mathrm{Hb} / \mathrm{mL}$ at the first or repeated screens were referred for colonoscopy on each occasion throughout the follow-up period from entry until the end of 2009. For adenoma, we classified abnormal findings by the number, site and size of adenomas found during each colonoscopy. Individuals with more than a single lesion were classified according to the most advanced. Prevalent adenoma and CRC cases were defined as the cases detected at first screen. Incident CRC cases included screen-detected cases (presymptomatic cases) detected by subsequent screens, interval 
cancers and cancers from non-participants of subsequent screen (symptomatic CRC). Interval cancers and cancers from non-participants were obtained through the linkage of the entire cohort with the nationwide cancer registry data and the follow-up of the entire cohort until the end of 2009. The national cancer registry is a nationwide resource with high coverage and accuracy (the percentage recorded as 'death certificate only' is less than $1 \%$ for CRC) but the time to reporting is around 3 years. In the present study, anthropometric measurements (including blood pressure, height, weight and waist circumference), information on demographic characteristics, family history and life-style (obtained from questionnaires) and a series of biochemical variables, including plasma triglycerides, high-density lipoprotein cholesterol and fasting glucose concentrations, were investigated and recorded at each visit.

Note that data derived from both cohorts and used for the following mortality data analysis consisted of the main variable of interest, $\mathrm{f}-\mathrm{Hb}$ and other confounding factors, all of which were collected at baseline (first screen) and the corresponding variables also collected at subsequent screens, which allowed us to do the following time-independent (baseline) and the timedependent Cox proportional hazards regression models (see below).

\section{Statistical analysis}

As far as descriptive analysis is concerned, we reported the detection rate at first screen (prevalence) for colorectal adenoma and CRC. It was calculated as the number of cases found divided by number of participants at first screen. By following up an adenoma-free or a CRC-free cohort (excluding individuals with CRC or colorectal adenoma detected at first screen), the incidence rates of CRC and colorectal adenoma were calculated as the number of incident cases identified during the follow-up divided by the number of person-years at risk.

A Cox proportional hazards regression model was used to investigate the possible causal effect of an incremental increase in $\mathrm{f}-\mathrm{Hb}$ on time to death from CRC. Time to event for each participant used in the regression analysis was calculated as the time from date of entry to the screening programme until date of death, date of loss to follow-up or the end of the study (whichever came first).

The concentration of $\mathrm{f}-\mathrm{Hb}$ was classified into eight incremental groups, the undetected, 1-19, 20-49, 50-99, 100-149, 150-249, 250-449 and $\geq 450 \mathrm{ng} \mathrm{Hb} / \mathrm{mL}$ following the previous study. ${ }^{11}$ In the univariate analysis, we estimated the crude HR (cHR) for each covariate including different categories of $\mathrm{f}-\mathrm{Hb}$ (main variable) and other confounding factors (including age, gender, smoking, drinking alcohol, body mass index (BMI), metabolic syndrome, diabetes mellitus and hypertension) collected at the same time as f-Hb. In the multivariable regression model, we tested whether each significant confounding factor identified from the univariate analysis was statistically significant when age, gender and $\mathrm{f}-\mathrm{Hb}$ were retained in the model. The baseline $\mathrm{f}-\mathrm{HB}$ was generally used in our time-independent analysis. However, to assess the effect of dynamic changes in $\mathrm{f}-\mathrm{Hb}$ on the risk for death, by screening round, a time-dependent, Cox proportional hazards regression model was used, treating the repeated data on $\mathrm{f}-\mathrm{Hb}$ collected from subsequent screens as timedependent covariates. Note that the last updated $\mathrm{f}-\mathrm{Hb}$ value near each time to event was used as the covariate of $\mathrm{f}-\mathrm{Hb}$ included in the time-dependent Cox proportional hazards regression model.

\section{RESULTS}

\section{CRC and neoplasia}

Table 1 shows the 217 CRC and 1246 adenoma that were identified at the first (prevalence) screen. For colorectal adenoma, the detection rate at the first screen increased with $\mathrm{f}-\mathrm{HB}$, from $11.2 \%$ among those screened with $\mathrm{f}-\mathrm{Hb}$ of 100 to $149 \mathrm{ng} \mathrm{Hb} / \mathrm{mL}$ to $15.6 \%$ among those with $\mathrm{f}-\mathrm{Hb} \geq 450 \mathrm{ng} \mathrm{Hb} / \mathrm{mL}$. Note that it was not possible to detect adenoma and CRC for $\mathrm{f}-\mathrm{Hb}$ below $100 \mathrm{ng} \mathrm{Hb} / \mathrm{mL}$ as these negative cases would not be referred to undergo colonoscopy. A similar increasing trend was found for CRC. Participants who were disease free at first screen were then followed up (the median follow-up time for the two cohorts combined was 3.5 years (IQR 1.4-5.3)) to identify 1016 incident cases of CRC and also 1394 incident cases of adenoma. The incidence rate (per 1000 persons) of colorectal adenoma increased with $\mathrm{f}-\mathrm{Hb}$, from 1.17 for $\mathrm{f}-\mathrm{Hb}$ of 1 to $19 \mathrm{ng} \mathrm{Hb} / \mathrm{mL}$ to 21.2 for $\mathrm{f}-\mathrm{Hb} \geq 450 \mathrm{ng} \mathrm{Hb} / \mathrm{mL}$ (table 1). A similar increasing trend was also noted for CRC.

\section{CRC mortality}

Table 1 and figure 1 show that the CRC mortality rate (per 1000 person-years) increased as the $\mathrm{f}-\mathrm{Hb}$ increased from 0.26 for 1 to $19 \mathrm{ng} \mathrm{Hb} / \mathrm{mL}$ to 3.54 for $\mathrm{f}-\mathrm{Hb} \geq 450 \mathrm{ng} \mathrm{Hb} / \mathrm{mL}$ (the far right column of table 1). Table 2 documents the cHR for age, gender, smoking, drinking alcohol, BMI, metabolic syndrome, diabetes mellitus, hypertension and $\mathrm{f}-\mathrm{Hb}$ based on Cox proportional hazards regression models. In the univariate analysis, we noted a direct effect of $\mathrm{f}-\mathrm{Hb}$ on the risk for CRC death, with the risk for those in the group with $\mathrm{f}-\mathrm{Hb}$ of $20-49 \mathrm{ng} \mathrm{Hb} / \mathrm{mL}$ being only slightly increased $(\mathrm{cHR}=1.02 ; 95 \%$ CI 0.65 to 1.60$)$ compared with the baseline category (1-19 $\mathrm{ng} \mathrm{Hb} / \mathrm{mL})$, whereas for $\mathrm{f}-\mathrm{Hb} \geq 450 \mathrm{ng} \mathrm{Hb} / \mathrm{mL}$, the risk increases 15-fold (CI 10.05 to 23.57 ; trend test, $\mathrm{p}<0.001)$. This significant impact persisted after adjustment for age, gender and diabetes mellitus in a multivariable analysis (trend test, $\mathrm{p}<0.001)$. Regarding other confounding factors, it should be noted that only diabetes mellitus remained statistically significant when age, gender and $\mathrm{f}-\mathrm{Hb}$ were retained in the multivariable regression model. Table 2 


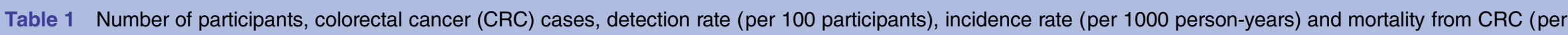
1000 person-years) in a CRC screening programme

\begin{tabular}{|c|c|c|c|c|c|c|c|c|c|c|c|}
\hline \multirow[b]{2}{*}{ Characteristics } & \multirow[b]{2}{*}{$\begin{array}{l}\text { Number of } \\
\text { participants }\end{array}$} & \multicolumn{4}{|l|}{ Adenoma } & \multicolumn{4}{|l|}{ CRC } & \multirow[b]{2}{*}{ Death } & \multirow[b]{2}{*}{$\begin{array}{l}\text { Mortality } \\
\text { rate }\end{array}$} \\
\hline & & $\begin{array}{l}\text { Prevalent } \\
\text { cases }\end{array}$ & $\begin{array}{l}\text { Detection } \\
\text { rate }\end{array}$ & $\begin{array}{l}\text { Incident } \\
\text { cases }\end{array}$ & $\begin{array}{l}\text { Incidence } \\
\text { rate }\end{array}$ & $\begin{array}{l}\text { Prevalent } \\
\text { cases }\end{array}$ & $\begin{array}{l}\text { Detection } \\
\text { rates }\end{array}$ & $\begin{array}{l}\text { Incident } \\
\text { cases }\end{array}$ & $\begin{array}{l}\text { Incidence } \\
\text { rate }\end{array}$ & & \\
\hline \multicolumn{12}{|l|}{ Age (years) } \\
\hline $40-49$ & 57153 & 123 & 0.22 & 147 & 0.68 & 32 & 0.06 & 89 & 0.41 & 13 & 0.06 \\
\hline $50-59$ & 53525 & 454 & 0.85 & 397 & 2.14 & 41 & 0.08 & 180 & 0.96 & 32 & 0.17 \\
\hline $60-69$ & 43663 & 514 & 1.18 & 699 & 4.63 & 66 & 0.15 & 348 & 2.29 & 57 & 0.37 \\
\hline$\geq 70$ & 31402 & 155 & 0.49 & 151 & 1.22 & 78 & 0.25 & 399 & 3.20 & 110 & 0.88 \\
\hline \multicolumn{12}{|l|}{ Gender } \\
\hline Male & 75267 & 816 & 1.08 & 803 & 3.14 & 123 & 0.16 & 502 & 1.94 & 104 & 0.40 \\
\hline Female & 110476 & 430 & 0.39 & 591 & 1.40 & 94 & 0.09 & 514 & 1.22 & 108 & 0.26 \\
\hline \multicolumn{12}{|l|}{$\mathrm{f}-\mathrm{Hb}$ (ng Hb/mL) } \\
\hline Undetected & 86574 & NK & 0.00 & 394 & 1.52 & NK & 0.00 & 226 & 0.87 & 49 & 0.19 \\
\hline $1-19$ & 62235 & NK & 0.00 & 300 & 1.17 & NK & 0.00 & 301 & 1.18 & 67 & 0.26 \\
\hline 20-49 & 19322 & NK & 0.00 & 187 & 1.92 & NK & 0.00 & 110 & 1.13 & 27 & 0.28 \\
\hline 50-99 & 8297 & NK & 0.00 & 88 & 2.39 & NK & 0.00 & 95 & 2.58 & 12 & 0.33 \\
\hline $100-149$ & 2850 & 318 & 11.16 & 103 & 10.20 & 34 & 1.19 & 31 & 2.80 & 8 & 0.71 \\
\hline $150-249$ & 2062 & 258 & 12.51 & 92 & 14.15 & 20 & 0.97 & 36 & 5.04 & 8 & 1.10 \\
\hline $250-449$ & 1522 & 221 & 14.52 & 72 & 17.39 & 21 & 1.38 & 38 & 8.05 & 10 & 2.09 \\
\hline$\geq 450$ & 2881 & 449 & 15.58 & 158 & 21.15 & 142 & 4.93 & 179 & 22.05 & 31 & 3.54 \\
\hline Total & 185743 & 1246 & 0.67 & 1394 & 2.06 & 217 & 0.12 & 1016 & 1.49 & 212 & 0.31 \\
\hline
\end{tabular}

The baseline $\mathrm{f}-\mathrm{Hb}$ was used.

$\mathrm{f}-\mathrm{Hb}$, faecal haemoglobin; NK, not known. 
Figure 1 Cumulative colorectal cancer mortality by an incremental increase in baseline faecal haemoglobin concentration.

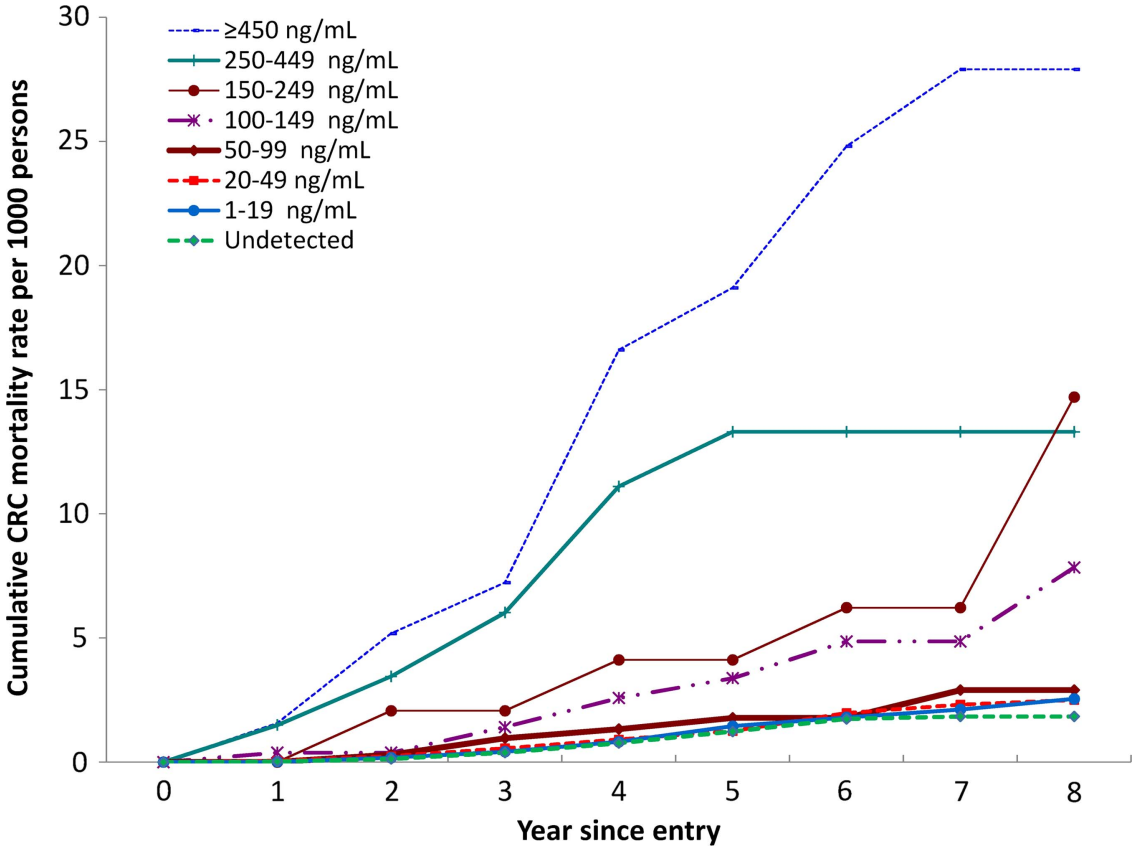

also shows the adjusted HR (aHR) when the repeated measurements of $\mathrm{f}-\mathrm{Hb}$ were treated as time-dependent covariates in the multivariable analysis. The aHR for CRC mortality increased from 1.09 (95\% CI 0.68 to 1.75 ) for $\mathrm{f}-\mathrm{Hb}$ of $20-49 \mathrm{ng} \mathrm{Hb} / \mathrm{mL}$ to 11.67 (95\% CI 7.71 to 17.66 ) for $\mathrm{f}-\mathrm{Hb} \geq 450 \mathrm{ng} \mathrm{Hb} / \mathrm{mL}$.

\section{All-cause death}

As shown in figure 2, a similar but less marked increasing trend was observed for all-cause death (per 1000 person-years), being 7.93 for those with the undetectable f-HB, 9.65 for $1-19,11.06$ for $20-49,13.74$ for 50-99, 13.44 for $100-149,18.21$ for $150-249$, 21.73 for 250-449 and 21.36 for $\geq 450 \mathrm{ng} \mathrm{Hb} / \mathrm{mL}$, respectively.

The effect of $\mathrm{f}-\mathrm{Hb}$ on all-cause death with the multivariable Cox proportional hazards regression model is documented in table 3. After adjusting for age and gender, the impact of $\mathrm{f}-\mathrm{Hb}$ on all-cause death was statistically significant (trend test, $\mathrm{p}<0.0001$ ) regardless of the model based on baseline or time-dependent f-Hb.

\section{DISCUSSION}

Our findings have significant implication for CRC screening in many countries with FIT. ${ }^{8}{ }^{15-20}$ This is the first population-based study, using data on populationbased screening for CRC with FIT, to demonstrate the effect of an incremental increase in f-Hb on CRC mortality and all-cause death. These findings strongly suggest that we could make a much better use of quantitative measures of $\mathrm{f}-\mathrm{Hb}$ as previously proposed. ${ }^{11} 21$ The increasing $\mathrm{f}-\mathrm{Hb}$ in groups, which strongly allude to an increase in CRC mortality, can be used to stratify the underlying population into different risk groups in order to consider the possibility of individually tailored screening policy of interscreening interval with reference to the values of $\mathrm{f}-\mathrm{Hb}$ at baseline to reduce false-negative cases and false-positive cases. To avoid the former, participants with higher $\mathrm{f}-\mathrm{Hb}$ but not yet classified as worthy of investigation for colorectal neoplasia at first screen may need a shorter interscreening interval with FIT or any further assessment of risk for CRC. On the other hand, the interval between repeated FIT screens could be extended to avoid false-positive cases for those with a lower $\mathrm{f}-\mathrm{Hb}$, particularly $50 \mathrm{ng} \mathrm{Hb} / \mathrm{mL}$ or below. However, further studies are required to elucidate the precise link between $\mathrm{f}-\mathrm{Hb}$ and objective proposals for individualised screening policies that will be widely adopted. Moreover, the optimal cut-off for individually tailored screening should be considered on the basis of cost-effectiveness analysis. This will become the subject of future research.

It is interesting to note the impact of $\mathrm{f}-\mathrm{Hb}$ on all-cause death. It could be argued that all-cause death may be mainly attributed to CRC deaths. However, the effect of $\mathrm{f}-\mathrm{Hb}$ on non-CRC deaths was still statistically significant ( $p<0.001$ for trend test) after excluding all CRC deaths. One biological explanation for this effect might be that an increase in $\mathrm{f}-\mathrm{Hb}$ leads to a decrease in systemic blood $\mathrm{Hb}$ concentration, ${ }^{22}$ which has been demonstrated in a previous study to be a strong predictor of all-cause death. ${ }^{23}$ However, we found the impact of $\mathrm{f}-\mathrm{Hb}$ on allcause death was attenuated, but still an independent predictor (aHR increased from 1.13 (1.04 to 1.22) for 20-49 $\mathrm{ng} \mathrm{Hb} / \mathrm{mL}$ to 1.63 (1.41 to 1.88 ) for $450 \mathrm{ng} \mathrm{Hb} / \mathrm{mL}$ or greater; trend test $\mathrm{p}<0.001)$ after adjusting for blood $\mathrm{Hb}$ concentration(low $\mathrm{Hb}$ vs higher $\mathrm{Hb} \quad(<13 \mathrm{~g} / \mathrm{dL}$ for men and $<12 \mathrm{~g} / \mathrm{dL}$ for women) with $\mathrm{aHR}=1.88(95 \%$ CI 1.77 to 1.99$)$ ). This finding may reduce this possibility but this postulate still needs to be verified. Another possible explanation is that an increase in $\mathrm{f}-\mathrm{Hb}$ is a reflection of systemic inflammation, as is the case with 
Table 2 Crude HRs and adjusted HRs (aHR) for CRC death in a CRC screening programme

\begin{tabular}{|c|c|c|c|c|c|c|}
\hline \multirow[b]{2}{*}{ Variables } & \multicolumn{2}{|c|}{ Univariate analysis } & \multicolumn{2}{|c|}{ Multivariate analysis } & \multicolumn{2}{|c|}{$\begin{array}{l}\text { Time-dependent } \\
\text { multivariate analysis }\end{array}$} \\
\hline & HR & $95 \% \mathrm{Cl}$ & $\overline{\text { aHR }}$ & $95 \% \mathrm{Cl}$ & $\overline{\text { aHR }}$ & $95 \% \mathrm{Cl}$ \\
\hline \multicolumn{7}{|l|}{ Age (years) } \\
\hline Comparison & 1.08 & $(1.07 \text { to } 1.09)^{\star *}$ & 1.08 & $(1.06 \text { to } 1.09)^{\star *}$ & 1.08 & $(1.06 \text { to } 1.09)^{\star \star}$ \\
\hline \multicolumn{7}{|l|}{ Gender } \\
\hline Male vs female & 1.65 & $(1.26 \text { to } 2.16)^{\star *}$ & 1.30 & (0.99 to 1.70$)$ & 1.28 & (0.98 to 1.68$)$ \\
\hline \multicolumn{7}{|l|}{ Smoking } \\
\hline Yes vs no & 1.21 & (0.89 to 1.66$)$ & & & & \\
\hline \multicolumn{7}{|l|}{ Drinking alcohol } \\
\hline Yes vs no & 0.91 & (0.65 to 1.29$)$ & & & & \\
\hline \multicolumn{7}{|l|}{ BMI $\left(\mathrm{kg} / \mathrm{m}^{2}\right)$} \\
\hline$\geq 30$ vs $<30$ & 1.22 & (0.76 to 1.95$)$ & & & & \\
\hline \multicolumn{7}{|c|}{ Metabolic syndrome } \\
\hline Yes vs no & 0.98 & (0.72 to 1.33$)$ & & & & \\
\hline \multicolumn{7}{|l|}{ Diabetes mellitus } \\
\hline Yes vs no & 2.22 & $(1.59 \text { to } 3.08)^{\star \star}$ & 1.69 & $(1.22 \text { to } 2.36)^{*}$ & 1.74 & $(1.25 \text { to } 2.42)^{\star}$ \\
\hline \multicolumn{7}{|l|}{ Hypertension } \\
\hline Yes vs no & 1.49 & $(1.13 \text { to } 1.96)^{*}$ & & & & \\
\hline \multicolumn{7}{|l|}{ f-Hb (ng Hb/mL) } \\
\hline Undetected & 0.83 & (0.57 to 1.20$)$ & 0.94 & (0.65 to 1.37$)$ & 0.81 & (0.55 to1.18) \\
\hline $1-19$ & 1.00 & & 1.00 & & 1.00 & \\
\hline 20-49 & 1.02 & (0.65 to 1.60$)$ & 1.01 & (0.65 to 1.58$)$ & 1.09 & (0.68 to 1.75$)$ \\
\hline $50-99$ & 1.23 & (0.67 to 2.27 ) & 1.09 & (0.59 to 2.02 ) & 1.21 & (0.66 to 2.25$)$ \\
\hline $100-149$ & 2.79 & (1.34 to 5.81 ) & 2.33 & (1.12 to 4.86$)$ & 2.54 & (1.26 to 5.09 ) \\
\hline $150-249$ & 4.48 & (2.15 to 9.33 ) & 3.39 & (1.63 to 7.07 ) & 2.76 & (1.27 to 6.03 ) \\
\hline $250-449$ & 8.90 & (4.58 to 17.31$)$ & 7.09 & (3.64 to 13.80 ) & 7.35 & (3.96 to 13.63 ) \\
\hline$\geq 450$ & 15.39 & $\begin{array}{l}\text { (10.05 to } 23.57) \\
\text { (trend test) }^{\star \star}\end{array}$ & 12.36 & $\begin{array}{l}\text { (8.04 to 18.99) } \\
\text { (trend test) }^{\star \star}\end{array}$ & 11.67 & $\begin{array}{l}(7.71 \text { to } 17.66) \\
\text { (trend test) }{ }^{\star \star}\end{array}$ \\
\hline \multicolumn{7}{|c|}{$\begin{array}{l}\text { ** } p<0.001 ;{ }^{*} \mathrm{p}<0.01 \text {. } \\
\text { Smoking status (yes: current or former smokers). } \\
\text { Drinking alcohol status (yes: current or former drinkers). } \\
\text { The metabolic syndrome was defined according to NCEP-modified ATP III criteria with the adjustment of waist circumference for Asian. } \\
\text { The values of } \mathrm{f}-\mathrm{Hb} \text { used in univariate and multivariate analysis were based on baseline (first screen) } \mathrm{f}-\mathrm{Hb} \text {. } \\
\text { The values of } \mathrm{f}-\mathrm{Hb} \text { used in time-dependant multivariate analysis were based on baseline (first screen) } \mathrm{f}-\mathrm{Hb} \text { and also repeated (subsequent } \\
\text { screen) } \mathrm{f}-\mathrm{Hb} \text {. } \\
\text { BMI, body mass index; CRC, colorectal cancer; } \mathrm{f}-\mathrm{Hb} \text {, faecal haemoglobin. }\end{array}$} \\
\hline
\end{tabular}

Figure 2 Cumulative all-cause death by an incremental increase in baseline faecal haemoglobin concentration.

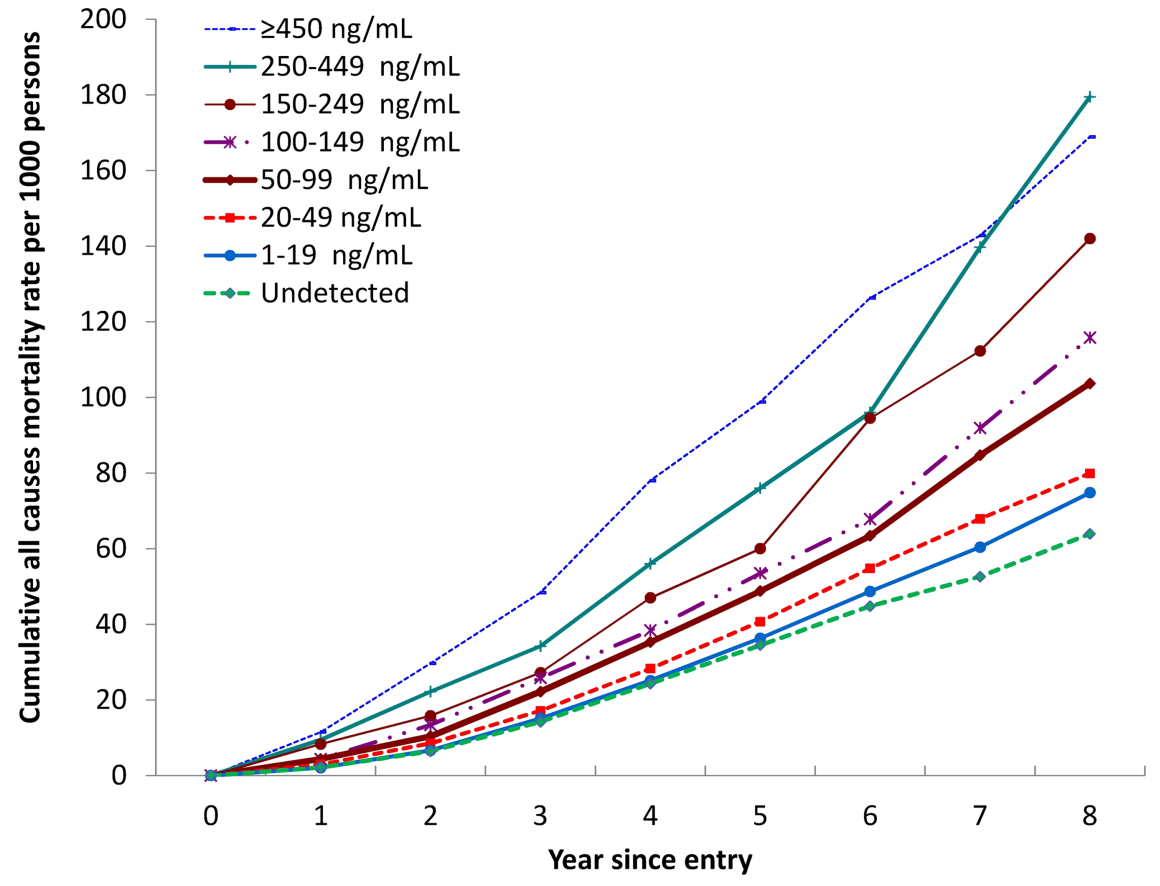


Table 3 Adjusted HRs (aHR) for death from all-causes

\begin{tabular}{|c|c|c|c|c|c|c|}
\hline \multirow[b]{2}{*}{ Variables } & \multicolumn{3}{|c|}{ Multivariate analysis } & \multicolumn{3}{|c|}{ Time-dependent multivariate analysis } \\
\hline & $\overline{\text { aHR }}$ & $95 \% \mathrm{Cl}$ & p Value & $\overline{\text { aHR }}$ & $95 \% \mathrm{Cl}$ & p Value \\
\hline \multicolumn{7}{|l|}{ Age (years) } \\
\hline Comparison & 1.10 & (1.09 to 1.10$)$ & $<0.0001$ & 1.10 & (1.09 to 1.10$)$ & $<0.0001$ \\
\hline \multicolumn{7}{|l|}{ Gender } \\
\hline Male vs female & 1.85 & (1.77 to 1.95$)$ & $<0.0001$ & 1.85 & (1.77 to 1.95$)$ & $<0.0001$ \\
\hline \multicolumn{7}{|l|}{$\mathrm{f}-\mathrm{Hb}(\mathrm{ng} \mathrm{Hb} / \mathrm{mL})$} \\
\hline Undetected & 1.06 & (1.00 to 1.12$)$ & & 1.00 & (0.95 to 1.06$)$ & \\
\hline $1-19$ & 1.00 & & & 1.00 & & \\
\hline $20-49$ & 1.03 & (0.97 to 1.11$)$ & & 1.15 & (1.07 to 1.24$)$ & \\
\hline 50-99 & 1.17 & (1.06 to 1.29$)$ & $<0.0001$ & 1.19 & (1.07 to 1.31 ) & $<0.0001$ \\
\hline $100-149$ & 1.14 & (0.97 to 1.35$)$ & (Trend test) & 1.20 & (1.03 to 1.41 ) & (Trend test) \\
\hline $150-249$ & 1.35 & (1.14 to 1.61 ) & & 1.32 & (1.11 to 1.57 ) & \\
\hline 250-449 & 1.73 & (1.42 to 2.11 ) & & 1.51 & (1.24 to 1.84 ) & \\
\hline$\geq 450$ & 1.78 & (1.54 to 2.07 ) & & 1.67 & (1.54 to 2.07 ) & \\
\hline
\end{tabular}

both chronic diseases (such as type 2 diabetes mellitus and cardiovascular disease) and CRC, in which there is an over expression of a number of inflammatory biomarkers such as tumour necrosis factors $\alpha$ and interleukin I-VI. ${ }^{24-27}$ We suggest that the impact of $\mathrm{f}-\mathrm{Hb}$ on all-cause death may be mediated through these inflammatory biomarkers. However, the exact mechanisms require further investigation.

The strengths of this study are that it examines the impact of $\mathrm{f}-\mathrm{Hb}$ on CRC mortality and all-cause deaths in two large cohorts of individuals over a long period of 8 years, making allowance for other possible confounding correlates (such as diabetes mellitus). As the main focus was the effect of an incremental increase in $\mathrm{f}-\mathrm{Hb}$ on CRC mortality, we have to control other confounding factors that may affect our main postulate because risk factors that are responsible for the occurrence of colorectal neoplasm may also lead to an increase in CRC mortality that is determined by the incidence and survival of CRC once our denominator is based on participants rather than colorectal neoplasm cases. To enhance the internal validity of our finding on the effect of $\mathrm{f}-\mathrm{Hb}$ on CRC mortality, we have to make allowance for these possible confounding factors by taking age, gender and diabetes mellitus into account in multivariable regression analysis in table 2. Furthermore, the analytical methodology used in this study is currently the most widely used quantitative measurement system for $\mathrm{f}-\mathrm{Hb}$ and has been proven to provide results of high quality. ${ }^{6}$

Potential weaknesses are several fold. First, the study was carried out over a period of time when some changes in procedures and practices might have occurred in spite of the ongoing total quality management techniques being applied throughout. Moreover, although it is now widely recognised that $\mathrm{f}-\mathrm{Hb}$ is dependent on age and gender, ${ }^{28}$ we did not specifically assess the effect of $\mathrm{f}-\mathrm{Hb}$ on CRC mortality and all-cause death in potential subgroups, but we undertook Cox proportional hazards' regression model to explore the effects of a number of variables including age and gender. Second, as our main interest was focused on the effect of $\mathrm{f}-\mathrm{Hb}$ on CRC mortality, we could only measure $\mathrm{f}-\mathrm{Hb}$ from participants involved in the screening programme. Thus, only measuring $\mathrm{f}-\mathrm{Hb}$ among participants and identifying the outcomes from these participants may be subject to selection bias if the baseline $\mathrm{f}-\mathrm{Hb}$ in participants were different from that in non-participant. This may suggest our finding may not be generalised to the entire underlying population but may be only applicable to those who had undertaken the screening programme. We believe such generalisability of our finding was not so serious because the Keelung cohort has almost covered the eligible population and the second cohort covered a large size of population. Moreover, as our community-based screening programme is a multiple service screening programme covering a range of different cancers and chronic diseases it seems unlikely to have the unknown selective factors leading to selection as often seen in a traditional cohort or case-control study that is tailored for testing the specific postulate. Third, although the effects of $\mathrm{f}-\mathrm{Hb}$ on CRC and all-cause mortality have been elucidated from our large population cohort, the longer follow-up time could strengthen this evidence if possible. The 3.5 years of median follow-up time might be a limitation of our study.

We substantiated the impact of an incremental increase in $\mathrm{f}-\mathrm{Hb}$ on CRC mortality, from a slightly increased risk for the category of $\mathrm{f}-\mathrm{Hb} 20-39 \mathrm{ng} \mathrm{Hb} / \mathrm{mL}$ to approximately 12 times risk for death for $\mathrm{f}-\mathrm{Hb}$ greater than $450 \mathrm{ng} \mathrm{Hb} / \mathrm{mL}$ compared with the baseline group of $\mathrm{f}-\mathrm{Hb}$ 1-19 $\mathrm{ng} \mathrm{Hb} / \mathrm{mL}$. The similar but less remarkable increasing trend was also noted for all-cause death. Both 
findings suggest that $\mathrm{f}-\mathrm{Hb}$ can not only be used for risk stratification of the underlying population to facilitate individually tailored screening for CRC but may also be a significant predictor for life-expectancy.

\section{Author affiliations}

${ }^{1}$ School of Oral Hygiene, College of Oral Medicine, Taipei Medical University, Taipei, Taiwan

${ }^{2}$ Centre for Research into Cancer Prevention and Screening, University of Dundee, Ninewells Hospital and Medical School, Dundee, Scotland ${ }^{3}$ Department and Graduate Institute of Health Care Management, Chang Gung University, Tao-Yuan, Taiwan

${ }^{4}$ Department of Health Industry Management, School of Healthcare Management, Kainan University, Tao-Yuan, Taiwan

${ }^{5}$ Keelung City Public Health Bureau, Keelung, Taiwan

${ }^{6}$ Tainan City Public Health Bureau, Tainan, Taiwan

${ }^{7}$ Division of Gastroenterology, Department of Internal Medicine, Shin-Kong Wu Ho-Su Memorial Hospital, Taipei, Taiwan

${ }^{8}$ Department of Internal Medicine, College of Medicine, National Taiwan University, Taipei, Taiwan

${ }^{9}$ Graduate Institute of Epidemiology and Preventive Medicine, College of Public Health, National Taiwan University, Taipei, Taiwan

Acknowledgements The authors would like to thank the Public Health Bureau of Keelung City and Tainan City for their contribution and support.

Contributors L-SC was responsible for writing up the manuscript, data management and also statistical analysis. AM-FY was responsible for statistical analysis and the interpretation of results. CGF was involved in the interpretation of results, and the edition of the manuscript. SY-HC and JC-YF were in charge of the data collection, linked the data of the two cohorts with mortality data, and did partial data analysis. P-EW and S-CL contributed to the implementation of programme, data collection and the interpretation of findings. C-SL, Y-CL and $\mathrm{H}-\mathrm{MC}$ were involved in auditing the clinical procedures, including colonoscopy examinations, the pathological confirmation of cases, the interpretation of the findings and discussion, and the revision of manuscript. $\mathrm{H}-\mathrm{HC}$ provided the main conceptual framework, designed the study, interpreted the results, supervised data analysis and revised the manuscript.

\section{Funding None.}

Competing interests None.

Patient consent Obtained.

Ethics approval This study was approved by Institutional Review Board of Taipei Medical University (TMU-JIRB No.201112024).

Provenance and peer review Not commissioned; externally peer reviewed.

Data sharing statement No additional data are available.

Open Access This is an Open Access article distributed in accordance with the Creative Commons Attribution Non Commercial (CC BY-NC 3.0) license, which permits others to distribute, remix, adapt, build upon this work noncommercially, and license their derivative works on different terms, provided the original work is properly cited and the use is non-commercial. See: http:// creativecommons.org/licenses/by-nc/3.0/

\section{REFERENCES}

1. Towler B, Irwig L, Glasziou $P$, et al. A systematic review of the effects of screening for colorectal cancer using the faecal occult blood test, hemoccult. BMJ 1998;317:559-65

2. Hewitson $P$, Glasziou $P$, Irwig $L$, et al. Screening for colorectal cancer using the faecal occult blood test, hemoccult. Cochrane Database Syst Rev 2007;(1):CD001216.

3. Young GP, Fraser CG, Halloran SP, et al. Guaiac-based faecal occult blood testing for colorectal cancer screening: an obsolete strategy? Gut 2012;61:959-60.

4. Fraser CG. A future for faecal haemoglobin measurements in the medical laboratory. Ann Clin Biochem 2012;49:518-26.

5. Halloran SP, Launoy G, Zappa M. Faecal occult blood testing In: Segnan N, Patnick J, von Karsa L, eds. European guidelines for quality assurance in colorectal cancer screening and diagnosis. 1st edn. Luxembourg: International Agency for Research on Cancer, Publications Office of the European Union, 2010:103-14.

6. Duffy MJ, van Rossum LGM, van Turenhout ST, et al. Use of faecal markers in screening for colorectal neoplasia: a European Group on Tumor Markers (EGTM) position paper. Int $J$ Cancer 2011;128:3-11.

7. Rabeneck L, Rumble RB, Thompson F, et al. Fecal immunochemical tests compared with guaiac fecal occult blood tests for population-based colorectal cancer screening. Can J Gastroenterol 2012;26:131-47.

8. Levi Z, Rozen P, Hazazi R, et al. A quantitative immunochemical fecal occult blood test for colorectal neoplasia. Ann Intern Med 2007;146:244-55

9. Fraser CG, Mathew CM, McKay K, et al. Automated immunochemical quantitation of haemoglobin in faeces collected on cards for screening for colorectal cancer. Gut 2008;57:1256-60.

10. Ciatto S, Martinelli F, Castiglione G, et al. Association of FOBT-assessed $\mathrm{f}-\mathrm{Hb}$ content with colonic lesions detected in the Florence screening programme. Br J Cancer 2007;96:218-21.

11. Chen LS, Yen AM, Chiu SY, et al. Baseline fecal occult blood concentration as a predictor of incident colorectal neoplasia: longitudinal follow-up of a Taiwanese population-based colorectal cancer screening cohort. Lancet Oncol 2011;12:551-8.

12. Chen $\mathrm{THH}$, Chiu YH, Luh DL, et al. Taiwan Community-based Integrated Screening Group. Community-based multiple screening model: design, implementation, and analysis of 42,387 participants. Cancer 2004;100:1734-43.

13. Yang $\mathrm{KC}$, Liao CS, Chiu $\mathrm{YH}$, et al. Colorectal cancer screening with fecal occult blood test within a multiple disease screening programme: an experience from Keelung, Taiwan. J Med Screen 2006;13:S8-13

14. Chen LS, Liao CS, Chang SH, et al. Cost-effectiveness analysis for determining optimal cut-off of immunochemical fecal occult blood test for population-based colorectal cancer screening (KCIS 16). J Med Screen 2007;14:191-9.

15. Flitcroft KL, St John DJ, Howard K, et al. A comparative case study of bowel cancer screening in the UK and Australia: evidence lost in translation? J Med Screen 2011;18:193-203.

16. Park MJ, Choi KS, Lee YK, et al. A comparison of qualitative and quantitative fecal immunochemical tests in the Korean national colorectal cancer screening program. Scand J Gastroenterol 2012;47:461-6.

17. Zorzi M, Fedato C, Grazzini G, et al. High sensitivity of five colorectal screening programmes with faecal immunochemical test in the Veneto Region, Italy. Gut 2011;60:944-9.

18. Lee $\mathrm{KJ}$, Inoue M, Otani $\mathrm{T}$, et al. Colorectal cancer screening using fecal occult blood test and subsequent risk of colorectal cancer: a prospective cohort study in Japan. Cancer Detect Prev 2007;31:3-11.

19. van Roon $\mathrm{AH}$, Goede SL, van Ballegooijen M, et al. Random comparison of repeated faecal immunochemical testing at different intervals for population-based colorectal cancer screening. Gut 2013;62:409-15.

20. Quintero E, Castells A, Bujanda L, et al. COLONPREV Study Investigators. Colonoscopy versus fecal immunochemical testing in colorectal-cancer screening. N Engl J Med 2012;366:697-706.

21. Fraser CG. Screening for colorectal neoplasia with faecal tests. Lancet Oncol 2011;12:516-17.

22. Barrows GH, Burton RM, Jarrett DD, et al. Immunochemical detection of human blood in feces. Am J Clin Pathol 1978;69:342-6.

23. Wu TH, Lee TK, Yen MF, et al. Long-term mortality assessment using biological measures among elderly people. Ten-year follow-up of 597 healthy elderly subjects in Taiwan. Fam Pract 2002;19:272-7.

24. Potter JD. Colorectal cancer: molecules and populations. J Natl Cancer Inst 1999;91:916-32.

25. Nikiteas NI, Tzanakis N, Gazouli M, et al. Serum IL-6, TNF-alpha and CRP levels in Greek colorectal cancer patients: prognostic implications. World J Gastroenterol 2005;11:1639-43.

26. Groblewska M, Mroczko B, Wereszczyńska-Siemiatkowska U, et al. Serum interleukin 6 (IL-6) and C-reactive protein (CRP) levels in colorectal adenoma and cancer patients. Clin Chem Lab Med 2008;46:1423-8.

27. Kim S, Keku TO, Martin C, et al. Circulating levels of inflammatory cytokines and risk of colorectal adenomas. Cancer Res 2008;68:323-8.

28. McDonald PJ, Strachan JA, Digby J, et al. Faecal haemoglobin concentrations by gender and age: implications for population-based screening for colorectal cancer. Clin Chem Lab Med 2012;50:935-40. 